\title{
Genotype by environment effects on promiscuous nodulation in soybean (Glycine max L. Merrill)
}

\author{
Eric E. Agoyi ${ }^{*}$, Thomas L. Odong ${ }^{1}$, John B. Tumuhairwe ${ }^{1}$, Godfree Chigeza ${ }^{3}$, Brian W. Diers ${ }^{2}$ \\ and Phinehas Tukamuhabwa'
}

\begin{abstract}
Background: Understanding factors influencing the expression of a trait is key in designing a breeding program. Genotype by environment interaction has great influence on most quantitative traits. Promiscuous nodulation is a trait of importance for soybean production in Africa, because of the soil bacteria Bradyrhizobium japonicum not being indigenous in most African soils. Most soybean cultivars require B. japonicum for nodulation leading to the need for seed inoculation before sowing soybean in Africa. Few cultivars have capability to nodulate with Bradyrhizobia spp. that are different from B. japonicum and native in African soils. Such cultivars are termed "promiscuous cultivars." Field experiments were conducted in six locations in Uganda for two seasons, to investigate the extent of environmental influences on the nodulation ability of promiscuous soybean genotypes.
\end{abstract}

Results: Additive main effect and multiplicative interaction effects showed highly significant environment and genotype by environment $(G \times E)$ interaction effects on all nodulation traits. $G \times E$ interaction contributed more to the total variation than genotypes. The genotypes Kabanyolo I and WonderSoya were the most stable for nodules' dry weight (NDW), which is the nodulation trait the most correlated with grain yield. Genotype UG5 was the most stable for nodules' number (NN), and Nam II for nodules' effectiveness (NE). The genotype NamSoy $4 \mathrm{M}$ had the highest performance for NN, NFW, and NDW, but was less stable. WonderSoya had the highest NE. Genotype and genotype by environment analysis grouped environments into mega-environments (MEs), and four MEs were observed for NDW, with NamSoy $4 \mathrm{M}$ the winning genotype in the largest ME, and Kasese B the ideal environment for that nodulation trait.

Conclusion: This study provides information that can guide breeding strategies. The low genetic effect that led to high environmental and $\mathrm{G} \times \mathrm{E}$ interaction effects raised the need for multi-environments testing before cultivar selection and recommendation. The study revealed genotypes that are stable and others that are high performing for nodulation traits, and which can be used as parental lines in breeding programs.

Keywords: Bradyrhizobium sp. USDA 3456, G × E, Nodulation, Promiscuous Soybean

\section{Background}

Crop genotypes respond differentially to diverse environments for most quantitative traits [1]. This differential response is known as genotype by environment $(\mathrm{G} \times \mathrm{E})$ interaction. Chandler et al. [2] reported that it is

\footnotetext{
*Correspondence: ericagoyi@gmail.com

1 Department of Agricultural Production, Makerere University,

P.O. Box 7062, Kampala, Uganda

Full list of author information is available at the end of the article
}

important to understand the causes of the $\mathrm{G} \times \mathrm{E}$ interaction in order to define breeding objectives. Gauch [3] and Yan and Hunt [4] argued that $\mathrm{G} \times \mathrm{E}$ interaction reduces selection progress in a breeding program and makes it difficult to select high-performing genotypes that are stable across locations. The impact of $\mathrm{G} \times \mathrm{E}$ on genotypes can be described by both their stability and adaptability. Stability is defined as the ability of a genotype to perform consistently in various environments. This applies 
to both high and low performance. Adaptability refers to the ability of a genotype to perform well in some environments and poorly in other environments [5]. Adaptability is handled by stratifying the production area and release of cultivars specifically adapted to each stratum [6]. Bernardo [7] found $\mathrm{G} \times \mathrm{E}$ interaction as both a problem and an opportunity. The author argued that a genotype with little $\mathrm{G} \times \mathrm{E}$ interaction is stable across environments; however, a genotype with high $\mathrm{G} \times \mathrm{E}$ interaction may outperform all other genotypes in specific environments, hence an opportunity to refine specific genotypes to specific environments. For a plant breeding program to be efficient, breeding strategies must integrate the environmental influence on the expression of genes involved in the traits under selection [8]. This is crucial at both cultivar selection and recommendation stages.

Promiscuous nodulation in soybean is a polygenic trait [9] of importance in Africa's soybean production. Nodules have ability to fix atmospheric nitrogen [10] which provides the plant with the required nitrogen for normal plant growth and soil improvement. Unfortunately, Bradyrhizobium japonicum, the symbiotic soil bacteria required for normal nodulation of soybean, is not present in most soils in Africa [11]. In addition, most farmers do not have access to B. japonicum inoculant that can be used to inoculate seed [12]. Promiscuous soybean genotypes which have the capability of nodulating with indigenous and readily available Bradyrhizobia [13] proved the best alternative, as they can achieve high yield without prior seed inoculation and thus rule out the need to inoculate seeds before planting.

Breeding for promiscuous soybean cultivars has proven successful. Scientists at the International Institute of Tropical Agriculture (IITA) have released promiscuous soybean lines which were found to efficiently nodulate with Bradyrhizobium spp. that belong to the cowpea "crossinoculation" group [14, 15]. Abaidoo et al. [16] detected Bradyrhizobium spp. populations in approximately $74 \%$ of the African soils; hence, promiscuous soybean cultivars would yield well without seed inoculation and ameliorate soils for subsequent crops in Africa. However, the genetics of promiscuous nodulation is not well documented and the little available literature is from [15]. They performed a backcross analysis of the dry weight of nodules and found that non-promiscuous phenotype was partially dominant and was controlled by four loci. The authors also based their investigation on leaf color score (LCS) and found that non-promiscuous phenotype was almost completely dominant in LCS. The same authors detected the RAPD marker OPB06 (5'-TGCTCTGCCC-3') which they reported to be consistent with the soybean genotypes segregating for promiscuous nodulation [17].
Several statistical methods are available to assess $\mathrm{G} \times \mathrm{E}$ interaction. These include analysis of variance (ANOVA), site regression analysis (SREG), genotype and genotype by environment (GGE) model, joint regression analysis (JREG), factorial regression analysis (FREG), shifted multiplicative model (SHMM), and additive main effect and multiplicative interaction effects (AMMI). The choice of a model for $G \times E$ interaction analyses depends on the objectives of the investigator [18]. Literature search shows that AMMI and GGE are currently the two most frequently used methods for $G \times E$ analyses. Several arguments have been advanced for or against the use of AMMI and GGE models. Gauch [19] showed that the advantage of AMMI over GGE resides in the fact that AMMI can distinguish the effects of the genotype and the environment and then assess the $\mathrm{G} \times \mathrm{E}$ interaction in a reduced space with minimum error. Gauch and Zobel [20] judged that AMMI was able to increase two to five times the number of replications, hence suitable for experiments with few replicates. Kandus et al. [18] stated that GGE has been widely used because it allows the visualization of genotype performance in each environment. Shrestha et al. [21] judged GGE as the best approach because it clearly shows the "which-won-where" pattern of the genotypes. Naroui Rad et al. [22] demonstrated that both AMMI and GGE are suitable for the demarcation of mega-environments as these authors reported similar results for both models. Moreover, [23] found that the AMMI model, the GGE model and the SHMM were equal in gaining accuracy in research.

The objective of this study was to investigate the magnitude of the $\mathrm{G} \times \mathrm{E}$ effect on promiscuous nodulation in soybean.

\section{Methods}

\section{Genetic material}

The study involved 12 soybean genotypes that were shown to be responsive to Bradyrhizobium sp. strain USDA 3456 (cowpea-type inoculant) in an earlier study [24] (Table 1).

\section{Experimental sites}

The study was conducted in six sites representing the major agroecologies in Uganda (Table 2):

- The Ngetta Zonal Agricultural Research and Development Institute (NZARDI) in Lira District, Northern Uganda.

- Nakabango Technology Verification Center in Jinja District, Eastern Uganda.

- Iki Iki Technology Verification Center in Budaka District, Eastern Uganda. 
Table 1 Description of genotypes used in the study

\begin{tabular}{lllll}
\hline Genotypes & Pedigree & Released & Current use status & Source \\
\hline Nam2 & TGM 79 & 1992 & Parental line & NARO, Uganda \\
MakSoy 3N & Gc00138-29 $\times$ Duiker & 2010 & Commercial & Mak, Uganda \\
NamSoy 4M & Nam2 $\times$ Gc00138-29 & 2004 & Commercial & NARO, Uganda \\
NamSoy 3 & Kabanyolo I $\times$ Nam I & 1995 & Parental line & NARO, Uganda \\
MakSoy 2N & MakSoy 1N $\times$ Duiker & 2008 & Commercial & Mak, Uganda \\
MakSoy 5N & Nam2 $\times$ Gc00138-29 & 2013 & Commercial & Mak, Uganda \\
Kabanyolo I & Mutant of Clark63 & - & Parental line & Mak, Uganda \\
WonderSoya & - & - & Parental line & IITA \\
Bulindi 48C & - & - & - & Mak, Uganda \\
Soprano & - & - & - & Zimbabwe \\
K-local & - & - & - & Uganda \\
UG5 & - & - & Uganda \\
\hline
\end{tabular}

NARO National Agricultural Research Organization, MAK Makerere University, IITA International Institute for Tropical Agriculture

- Mubuku Irrigation and Resettlement Center in Kasese District, Western Uganda.

- Makerere University Agricultural Research Institute of Kabanyolo (MUARIK), Central Uganda.

- On-farm trial in Kamwenge District, Western Uganda.

\section{Preparation of inoculum, planting, and data collection}

At each site, plots of land not previously artificially inoculated with Bradyrhizobia were selected and prepared for sowing following common land preparation methods [25]. Seeds of the 12 genotypes were inoculated with Bradyrhizobium sp. strain USDA 3456 (cowpea-type inoculant). Bradyrhizobium spp. are reported to effectively nodulate promiscuous soybean genotypes $[14,15]$. Inoculant was obtained from Biofix (Kenya), purified, and incubated in the Soil Science Biological Nitrogen Fixation (BNF) Laboratory at Makerere University. The most probable number (MPN) through serial dilution technique described in [26] was used to grow Bradyrhizobium to $7.91 \times 10^{9}$ cells $\mathrm{g}^{-1}$ and then formulated into inoculum using steam-sterilized peat soil as a carrier. Ten grams of sugar was dissolved into $300 \mathrm{ml}$ of clean lukewarm water to produce a sticking agent. The inoculant was mixed with the sticking agent and directly applied on seeds to enhance association between plant and rhizobium. To be sure that inoculants were viable, fresh culture was made at each planting season, and after mixing with peat soil, packets were refrigerated at $4{ }^{\circ} \mathrm{C}$ until planting date.

The field experiments were arranged in a randomized complete block design (RCBD) with three replicates at each site. Each plot was three rows wide and $5 \mathrm{~m}$ in length. The rows were $0.6 \mathrm{~m}$ apart with a spacing of $0.1 \mathrm{~m}$ between plants within rows, giving an average of 153 plants per plot (170,000 plants/ha). Experiments were conducted for two consecutive seasons: first rainy season (2015A) and second rainy season (2015B) of 2015 at each site, resulting in 12 testing environments (see Table 3 ). Fields were weeded three times in a season.

At each of the six sites, 6-7 weeks after emergence (see planting and sampling dates in Table 3), ten plants per plot were randomly dug up, the root system from each plant was carefully washed, and all nodules were

Table 2 Agro-climatic description of the six experimental sites used in the study

\begin{tabular}{|c|c|c|c|c|c|c|c|}
\hline \multirow[t]{2}{*}{ Sites } & \multirow[t]{2}{*}{ Latitude } & \multirow[t]{2}{*}{ Longitude } & \multirow[t]{2}{*}{ Elevation (masl) } & \multirow{2}{*}{$\begin{array}{l}\text { Mean rainfall } \\
(\mathrm{mm})\end{array}$} & \multicolumn{2}{|c|}{ Temperature $\left({ }^{\circ} \mathrm{C}\right)$} & \multirow[t]{2}{*}{ Soil type } \\
\hline & & & & & Min & Max & \\
\hline (MUARIK) Kabanyolo & 0.45 & 32.61 & 1300 & 1255 & 21.9 & 28.1 & Ferralitic soils \\
\hline Mubuku (Kasese) & 0.18 & 30.0833 & 930 & 1200 & 18 & 31 & Peaty, sands and clays \\
\hline Kamwenge & 0.18 & 30.45 & 1300 & 1300 & 20 & 25 & Ferralsols, acrisols, nitosols \\
\hline Nakabango (Jinja) & 0.42 & 33.20 & 1178 & 1400 & 15 & 26 & Crystalline basic \\
\hline Iki Iki (Budaka) & 1.09 & 34.00 & 1156 & 1200 & 15 & 28 & Sandy \\
\hline Ngetta (Lira) & 53.69 & 22.93 & 1300 & 1483 & 19 & 29 & Sandy loam \\
\hline
\end{tabular}

mas/ meters above sea level 
Table 3 Planting and sampling dates, $\mathrm{pH}$, and nutrient contents of soil sampled from experiment sites during seasons 2015A and 2015B

\begin{tabular}{|c|c|c|c|c|c|c|c|c|c|c|c|}
\hline Sites & Seasons & $\begin{array}{l}\text { Planting date } \\
\text { (dd/mm) }\end{array}$ & $\begin{array}{l}\text { Sampling date } \\
(\mathrm{dd} / \mathrm{mm})\end{array}$ & $\mathrm{pH}$ & o.m. (\% age) & $\mathrm{N}(\mathrm{mg} / \mathrm{kg})$ & Av. P (C mol/kg) & K & $\mathrm{Na}$ & $\mathrm{Ca}$ & $\mathrm{Mg}$ \\
\hline \multirow[t]{2}{*}{ Kabanyolo } & $2015 A$ & 01/04 & $23 / 05$ & 4.92 & 2.64 & 0.26 & 4.48 & 0.38 & 0.20 & 2.80 & 0.84 \\
\hline & $2015 B$ & 18/09 & $12 / 11$ & 4.86 & 2.66 & 0.24 & 4.51 & 0.37 & 0.21 & 2.70 & 0.81 \\
\hline \multirow[t]{2}{*}{ Ngetta } & $2015 A$ & $12 / 04$ & 05/06 & 4.78 & 1.93 & 0.19 & 4.20 & 0.21 & 0.17 & 2.50 & 0.75 \\
\hline & 2015B & 20/09 & $14 / 11$ & 6.11 & 1.91 & 0.14 & 12.31 & 0.76 & 0.60 & 4.56 & 1.50 \\
\hline \multirow[t]{2}{*}{ Kamwenge } & $2015 A$ & 03/04 & $26 / 05$ & 4.95 & 2.29 & 0.23 & 4.48 & 0.18 & 0.20 & 3.13 & 0.94 \\
\hline & 2015B & $14 / 10$ & $10 / 12$ & 5.45 & 2.50 & 0.18 & 7.45 & 0.32 & 0.05 & 3.12 & 1.03 \\
\hline \multirow[t]{2}{*}{ Kasese } & $2015 A$ & $02 / 04$ & $25 / 05$ & 5.07 & 3.34 & 0.33 & 17.82 & 0.32 & 0.09 & 5.32 & 1.60 \\
\hline & 2015B & $13 / 10$ & 09/12 & 5.08 & 3.29 & 0.31 & 17.77 & 0.33 & 0.11 & 5.29 & 1.58 \\
\hline \multirow[t]{2}{*}{ Iki Iki } & $2015 A$ & 09/04 & 02/06 & 5.39 & 1.76 & 0.18 & 4.41 & 0.25 & 0.24 & 2.19 & 0.66 \\
\hline & 2015B & $26 / 09$ & $30 / 11$ & 5.41 & 1.77 & 0.19 & 4.45 & 0.27 & 0.23 & 2.21 & 0.70 \\
\hline \multirow[t]{2}{*}{ Nakabango } & $2015 A$ & 08/04 & $01 / 06$ & 5.12 & 3.52 & 0.35 & 4.55 & 0.42 & 0.20 & 5.00 & 1.50 \\
\hline & 2015B & 25/09 & 29/11 & 5.17 & 3.55 & 0.34 & 4.55 & 0.43 & 0.22 & 4.87 & 1.46 \\
\hline
\end{tabular}

Av. $P$ available phosphorus, o.m. organic matter, $d d / m m$ day/month

harvested and counted to determine the number of nodules $(\mathrm{NN})$, and later weighed to determine the fresh weight of nodules per plant (NFW). Thereafter, all the nodules were split and opened to assess their effectiveness. The percentage of effective nodules (NE) per plant was calculated based on the presence of brownish or pinkish pigmentation inside nodules. Nodules were then oven-dried at $65{ }^{\circ} \mathrm{C}$ for 4 days [15] and weighed to determine the total nodule dry weight (NDW) per plant.

\section{Data analysis}

ANOVA was performed for each site separately followed by a combined analysis across sites in GenStat 14th edition (VSN International Ltd., Hemel Hempstead, UK) [27]. No data transformation was needed.

The models for analyses were:

$$
\begin{aligned}
Y_{i j k}= & \mu+G_{i}+S_{j}+G S_{i j}+S / r_{j k}+\varepsilon_{i j k} \\
& (\text { for single site analysis) } \\
Y_{i j h k}= & \mu+G_{i}+L_{h}+S_{j}+G L_{i h}+G S_{i j} \\
& +L S_{h j}+G L S_{i h j}+E / r_{j h k}+\varepsilon_{i j h k}
\end{aligned}
$$

(for across environments analysis)

where $Y_{i j k}$ is the observed value from each experimental unit, $\mu$ population mean, $L_{h}$ effect of the $h$ th site, $S_{j}$ effect of the $j$ th season, $S / r_{j k}$ effect of the $k$ th replicate nested to the $j$ th season, $E / r_{j h k}$ effect of the $k$ th replicate nested to the $j h$ th environment (environment = location by season), $G_{i}$ effect of $i$ th genotype, $G S_{i j}$ interaction effect of $i$ th genotype and the $j$ th season, $L S_{j h}$ effect of the $j$ th season nested to the $h$ th location, $G L S_{i j h}$ interaction effect of $i$ th genotype and the $j h$ th environment (site per season) and $\varepsilon_{i j k h}$ experimental error.
AMMI analysis was performed on each nodulation trait to determine the contribution of the genotypes, environments, as well as their interaction to the total variation.

GGE analysis was also performed to determine the mega-environments and visualize the "which-wonwhere" pattern. These were done using breeding view graphical user interface with a statistical analysis package [28] embedded in Breeding Management System (BMS) Version 3.0.9.

\section{Results}

Analysis of variance

The single site ANOVA (Table 4) showed significant differences $(p<0.05)$ among genotypes for all nodulation traits measured at most of the sites, except at Iki Iki where genotype effects were nonsignificant for all nodulation traits. Percentage of effective nodules was not significant $(p>0.05)$ at Kabanyolo and Kamwenge.

Season effects were significant $(p<0.05)$ for all nodulation traits at Nakabango. There were no significant $(p>0.05)$ season effects for the percentage of NE at Iki Iki, Kabanyolo, and Ngetta, while season effects for NN were nonsignificant at Kabanyolo, Kamwenge, and Kasese. Season had significant effects on dry weight of nodules at all sites except at Kamwenge.

There was significant genotype by season effects for $\mathrm{NN}$ at Kasese and Ngetta. For NE, significant genotype by season effects was only obtained at Ngetta, while NFW had significant genotype by season effects at Kamwenge, Kasese, and Ngetta. Significant genotype by season effects for NDW was also obtained at Iki Iki and Ngetta. Ngetta exhibited significant genotype by season effects on all nodulation traits. The interaction between 
Table 4 Summary of ANOVA results of single site analysis for all the nodulation traits measured during seasons 2015A and 2015B

\begin{tabular}{|c|c|c|c|c|c|c|}
\hline \multirow[t]{2}{*}{ Sites } & \multirow[t]{2}{*}{ Sources } & \multirow[t]{2}{*}{$d f$} & \multicolumn{4}{|l|}{ m.s. } \\
\hline & & & $\mathrm{NN}$ & $\mathrm{NE}$ & NFW & NDW \\
\hline \multirow[t]{7}{*}{ Iki Iki } & Seasons & 1 & $2485.12^{* *}$ & $425.0^{\text {ns }}$ & $3.692^{* *}$ & $0.061^{*}$ \\
\hline & Genotypes & 11 & $38.74^{\text {ns }}$ & $434.8^{\text {ns }}$ & $0.057^{\mathrm{ns}}$ & $0.002^{\mathrm{ns}}$ \\
\hline & Genotypes $\times$ seasons & 11 & $57.16^{\mathrm{ns}}$ & $479.9^{\text {ns }}$ & $0.069^{\text {ns }}$ & $0.004^{*}$ \\
\hline & Error & 44 & 36.73 & 299.6 & 0.047 & 0.002 \\
\hline & Mean & & 10 & 57.6 & 0.43 & 0.074 \\
\hline & CV (\%) & & 60 & 30 & 50 & 55 \\
\hline & SEM & & 2.02 & 5.77 & 0.072 & 0.0014 \\
\hline \multirow[t]{7}{*}{ Kabanyolo } & Seasons & 1 & $3.65^{\text {ns }}$ & $244.96^{\mathrm{ns}}$ & $1.5851^{* *}$ & $0.1910^{* * *}$ \\
\hline & Genotypes & 11 & $566.53^{* * *}$ & $150.76^{\text {ns }}$ & $0.1001^{* * *}$ & $0.0061^{* *}$ \\
\hline & Genotypes $\times$ seasons & 11 & $119.63^{\mathrm{ns}}$ & $115.38^{\mathrm{ns}}$ & $0.0221^{\mathrm{ns}}$ & $0.0020^{\text {ns }}$ \\
\hline & Error & 44 & 98.26 & 87.59 & 0.0286 & 0.0018 \\
\hline & Mean & & 31 & 68.3 & 0.404 & 0.101 \\
\hline & $C V(\%)$ & & 32 & 13.7 & 41.86 & 42 \\
\hline & SEM & & 3.3 & 3.12 & 0.056 & 0.014 \\
\hline \multirow[t]{7}{*}{ Kamwenge } & Seasons & 1 & $7.35^{\mathrm{ns}}$ & $7171^{*}$ & $0.0007^{\mathrm{ns}}$ & $0.0005^{\text {ns }}$ \\
\hline & Genotypes & 11 & $1.31^{*}$ & $2690^{\text {ns }}$ & $0.0187^{* * *}$ & $0.0002^{* * *}$ \\
\hline & Genotypes $\times$ seasons & 11 & $1.03^{\mathrm{ns}}$ & $381 \mathrm{~ns}$ & $0.0082^{* *}$ & $0.0001^{\mathrm{ns}}$ \\
\hline & Error & 44 & 0.57 & 1242 & 0.0033 & 0.0001 \\
\hline & Mean & & 1 & 66.8 & 0.039 & 0.0049 \\
\hline & CV (\%) & & 75 & 52.75 & 147.29 & 204.08 \\
\hline & SEM & & 0.25 & 11.74 & 0.019 & 0.0033 \\
\hline \multirow[t]{7}{*}{ Kasese } & Seasons & 1 & $3389.39^{\text {ns }}$ & $1241.49^{* *}$ & $2.3852^{*}$ & $0.3966^{* *}$ \\
\hline & Genotypes & 11 & $523.13^{* * *}$ & $175.95^{*}$ & $0.7319^{* * *}$ & $0.0288^{* *}$ \\
\hline & Genotypes $\times$ seasons & 11 & $471.16^{* * *}$ & $78.58^{\text {ns }}$ & $0.3612^{* *}$ & $0.0074^{\mathrm{ns}}$ \\
\hline & Error & 44 & 96.54 & 85.91 & 0.1460 & 0.0115 \\
\hline & Mean & & 30 & 82.1 & 1.214 & 0.254 \\
\hline & CV (\%) & & 32.75 & 11.28 & 31.47 & 42.21 \\
\hline & SEM & & 3.27 & 3.08 & 0.12 & 0.035 \\
\hline \multirow[t]{7}{*}{ Ngetta } & Seasons & 1 & $95.22^{*}$ & $155.5^{\text {ns }}$ & $0.1982^{* *}$ & $0.0076^{* * *}$ \\
\hline & Genotypes & 11 & $33.44^{* * *}$ & $1960.0^{* *}$ & $0.0703^{* * *}$ & $0.0023^{* * *}$ \\
\hline & Genotypes $\times$ seasons & 11 & $23.40^{* * *}$ & $3869.6^{* * *}$ & $0.0360^{* * *}$ & $0.0012^{* * *}$ \\
\hline & Error & 44 & 4.01 & 548.8 & 0.0067 & 0.0002 \\
\hline & Mean & & 2 & 62.4 & 0.1223 & 0.0187 \\
\hline & CV (\%) & & 100 & 37.54 & 66.92 & 75.62 \\
\hline & SEM & & 0.66 & 7.80 & 0.11 & 0.045 \\
\hline \multirow[t]{7}{*}{ Nakabango } & Seasons & 1 & $14,308.7^{* *}$ & $452.2^{*}$ & $11.4899^{* *}$ & $0.6253^{* *}$ \\
\hline & Genotypes & 11 & $638.6^{*}$ & $587.7^{* *}$ & $0.3470^{* *}$ & $0.0173^{* *}$ \\
\hline & Genotypes $\times$ seasons & 11 & $206.8^{\text {ns }}$ & $276.2^{\text {ns }}$ & $0.1241^{\mathrm{ns}}$ & $0.0056^{\text {ns }}$ \\
\hline & Error & 44 & 279.8 & 179.3 & 0.1022 & 0.0059 \\
\hline & Mean & & 39 & 64.8 & 1.017 & 0.2346 \\
\hline & CV (\%) & & 42.89 & 20.66 & 31.43 & 32.74 \\
\hline & SEM & & 5.57 & 4.46 & 0.106 & 0.0256 \\
\hline
\end{tabular}

$d f$ degree of freedom, m.s. mean square, $N N$ number of nodules, NE percentage of effective nodules, NFW fresh weight of nodules, NDW dry weight of nodules

* Significant at 0.05

** Significant at 0.01

*** Significant at 0.001 
genotypes and seasons was not significant for any nodulation trait at Kabanyolo and Nakabango.

In the analysis across all 12 environments, genotype by environment effects was highly significant for $\mathrm{NN}$, NE, NFW $(p<0.001)$, and NDW $(p<0.05)$ (Table 5). Highly significant $(p<0.001)$ genotypic effects were also obtained for all nodulation traits except NE, where there was no significant difference between genotypes across environments. Highly significant environmental effects were observed for all nodulation traits $(p<0.001)$. The interaction of genotypes $\times$ sites $\times$ seasons was highly significant $(p<0.01)$ for all nodulation traits except for NDW. Sites showed significant differences only for NN and NE, while seasons showed significant difference only for NE. The interaction of sites $\times$ seasons was highly significant $(p<0.001)$ for all nodulation traits, except for NE. There was significant interaction between genotypes and sites for NFW and NDW, while no significant interaction was observed between genotypes and seasons for any of the nodulation traits measured.

\section{Additive main effect and multiplicative interaction (AMMI) analysis}

The AMMI ANOVA (Table 6) showed significant effects of genotypes and environments as well as their interactions for all nodulation traits $(p<0.05-p<0.001)$, except for the percentage of effective nodules, where genotypic effects were not significant. The first two interaction principal component axes (IPCA) were significant at $(p<0.01)$ for all nodulation traits. For all nodulation traits, the first IPCA explained more than $50 \%$ of the total variation. IPCA1 explained $56.8 \%$ of the total variation in NN, $69.86 \%$ for NE, $61.13 \%$ for NFW and $72.11 \%$ for NDW, while IPCA2 explained $43.2 \%$ for NN, 30.14\% for NE, $38.87 \%$ for NFW and $27.89 \%$ for NDW.

$\mathrm{G} \times \mathrm{E}$ interaction had a substantial contribution to the total variation for all nodulation traits, varying from 9 to $64 \%$ (Table 6). The highest $\mathrm{G} \times \mathrm{E}$ effect was observed for NE, while the lowest $G \times E$ effect was observed for NDW. Environments had the highest contribution (13$84 \%$ ) to the total sum of squares for all nodulation traits except for NE, where the highest contribution $(64 \%)$ was from the $G \times E$ interaction. Genotypes had the lowest contribution $(3.9-6.0 \%)$ to the total variation, suggesting low genetic effect and high environmental effect in the expression of the nodulation traits measured.

The AMMI biplots (Fig. 1) showed the genotype NamSoy $4 \mathrm{M}$ with the highest $\mathrm{NN}$ across environments (29 nodules per plant), while K-local had the lowest performance (11 nodules per plant). These two genotypes were both unstable as they are far from the origin with regard to the $y$ axis, while the genotype UG5 proved the most stable.

As for the percentage of NE, the most stable genotypes were Nam II, Kabanyolo I, and NamSoy 3. MakSoy 2N was the most unstable, far apart from the origin, and had a relatively high performance across environments $(72 \%$ of effective nodules). The genotype WonderSoya had the highest performance across environments ( $74 \%$ of effective nodules), coupled with a relatively high stability, while the genotype Soprano had the lowest performance (56\% of effective nodules) and was relatively unstable.

Table 5 Summary of ANOVA results across environments for all the nodulation traits measured during seasons 2015A and 2015B

\begin{tabular}{|c|c|c|c|c|c|}
\hline \multirow[t]{2}{*}{ Source } & \multirow[t]{2}{*}{$d f$} & \multicolumn{4}{|l|}{ m.s. } \\
\hline & & NN & $\mathrm{NE}$ & NFW & NDW \\
\hline Environment & 11 & $10,730.32^{* * *}$ & $2333.2^{* * *}$ & $9.20^{* * *}$ & $0.49^{* * *}$ \\
\hline Locations & 5 & $19,548.83^{*}$ & $4416.34^{* *}$ & $16.36^{\text {ns }}$ & $0.82^{\mathrm{ns}}$ \\
\hline Seasons & 1 & $6.85^{\mathrm{ns}}$ & $2696.6^{*}$ & $0.54^{\mathrm{ns}}$ & $0.05^{\mathrm{ns}}$ \\
\hline Locations $\times$ seasons & 5 & $4056.51^{* * *}$ & $177.38^{\text {ns }}$ & $3.76^{* * *}$ & $0.24^{* * *}$ \\
\hline Reps (environment) & 24 & $308.53^{* * *}$ & $461.66^{*}$ & $0.11^{* *}$ & $0.01^{* *}$ \\
\hline Genotypes & 11 & $837.6^{* * *}$ & $749.91^{\mathrm{ns}}$ & $0.53^{* * *}$ & $0.02^{* * *}$ \\
\hline Genotypes $\times$ environment & 121 & $167.57^{* * *}$ & $603.66^{* * *}$ & $0.13^{* * *}$ & $0.005^{*}$ \\
\hline Genotypes $\times$ locations & 55 & $192.82^{\text {ns }}$ & $600.80^{\text {ns }}$ & $0.16^{*}$ & $0.006^{* *}$ \\
\hline Genotypes $\times$ seasons & 11 & $186.51^{\text {ns }}$ & $335.92^{\text {ns }}$ & $0.14^{\mathrm{ns}}$ & $0.003^{\mathrm{ns}}$ \\
\hline Genotypes $\times$ locations $\times$ seasons & 55 & $138.54^{* *}$ & $672.61^{* * *}$ & $0.09^{* *}$ & $0.003^{\mathrm{ns}}$ \\
\hline Error & 264 & 85.98 & 277.57 & 0.05 & 0.003 \\
\hline
\end{tabular}

df degree of freedom, $m$.s. mean square, $N N$ number of nodules, NE percentage of effective nodules, NFW fresh weight of nodules, NDW dry weight of nodules

* Significant at 0.05

** Significant at 0.01

*** Significant at 0.001 


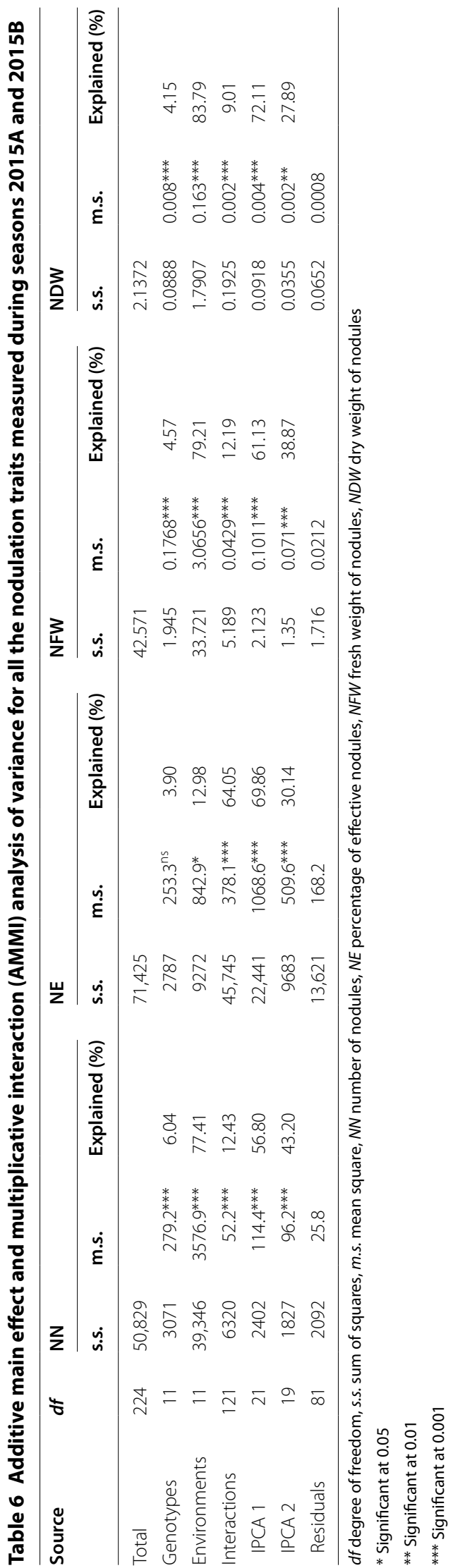



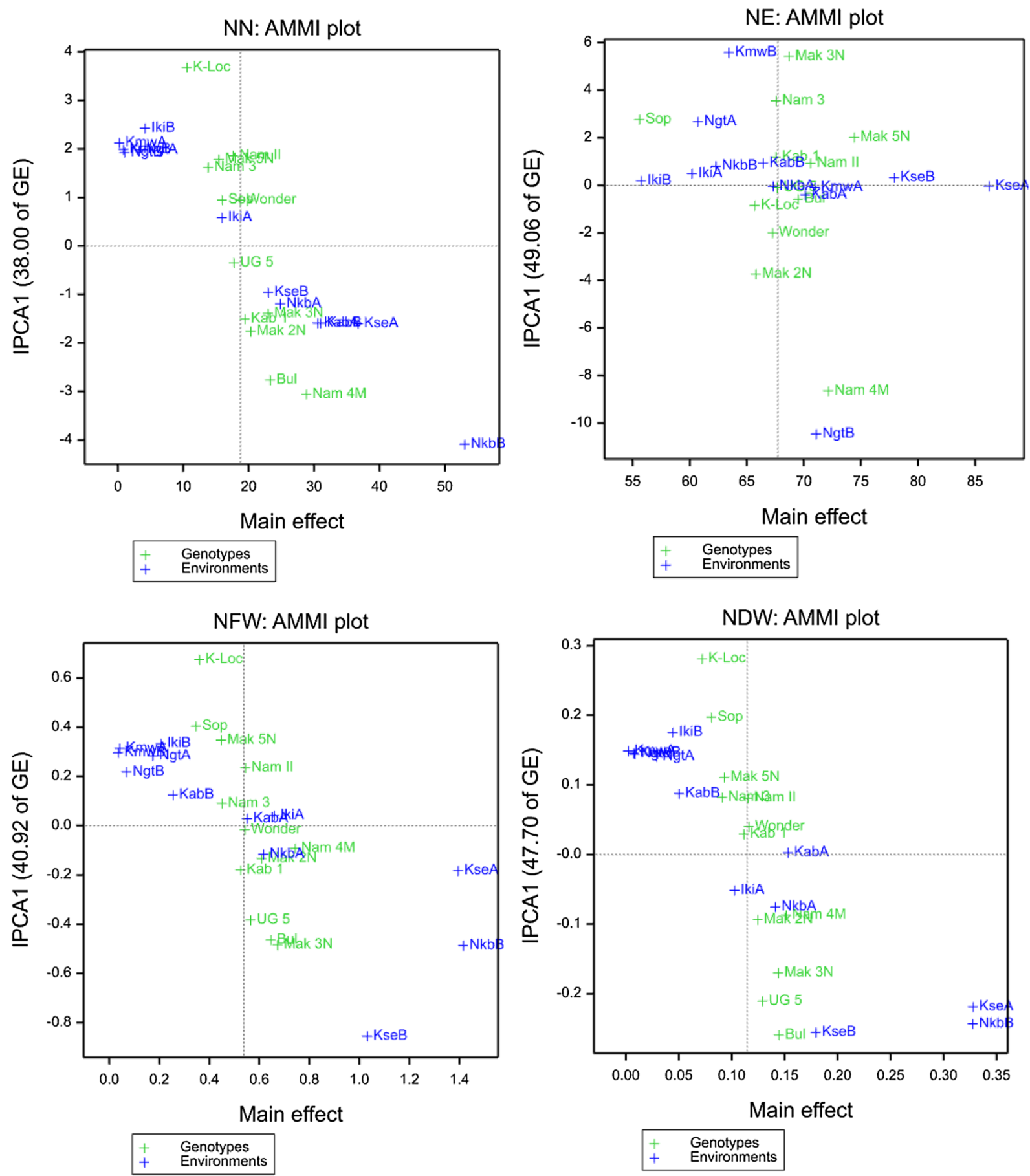

Fig. 1 AMMI1 Biplots for nodulation traits of soybean genotypes showing genotypes' means (in green color) and environments (in blue color) plotted against their IPCA1 scores. Mak 3N MakSoy 3N, Nam 4M NamSoy 4M, Nam 3 NamSoy3, Mak 2N MakSoy 2N, Mak 5 N MakSoy 5N, Kab I Kabanyolo I, Wonder WonderSoya, Bul Bulindi 48C, Sop Soprano, K-Loc K-local, IkiA Iki Iki season A, IkiB Iki Iki season B, KabA Kabanyolo season A, KabB Kabanyolo season B, Kam A Kamwenge season A, KamB Kamwenge season B, KasA Kasese season A, KasB Kasese season B, NgtA Ngetta season A, NgtB Ngetta season B, NkgA Nakabango season A, NkgB Nakabango season B 


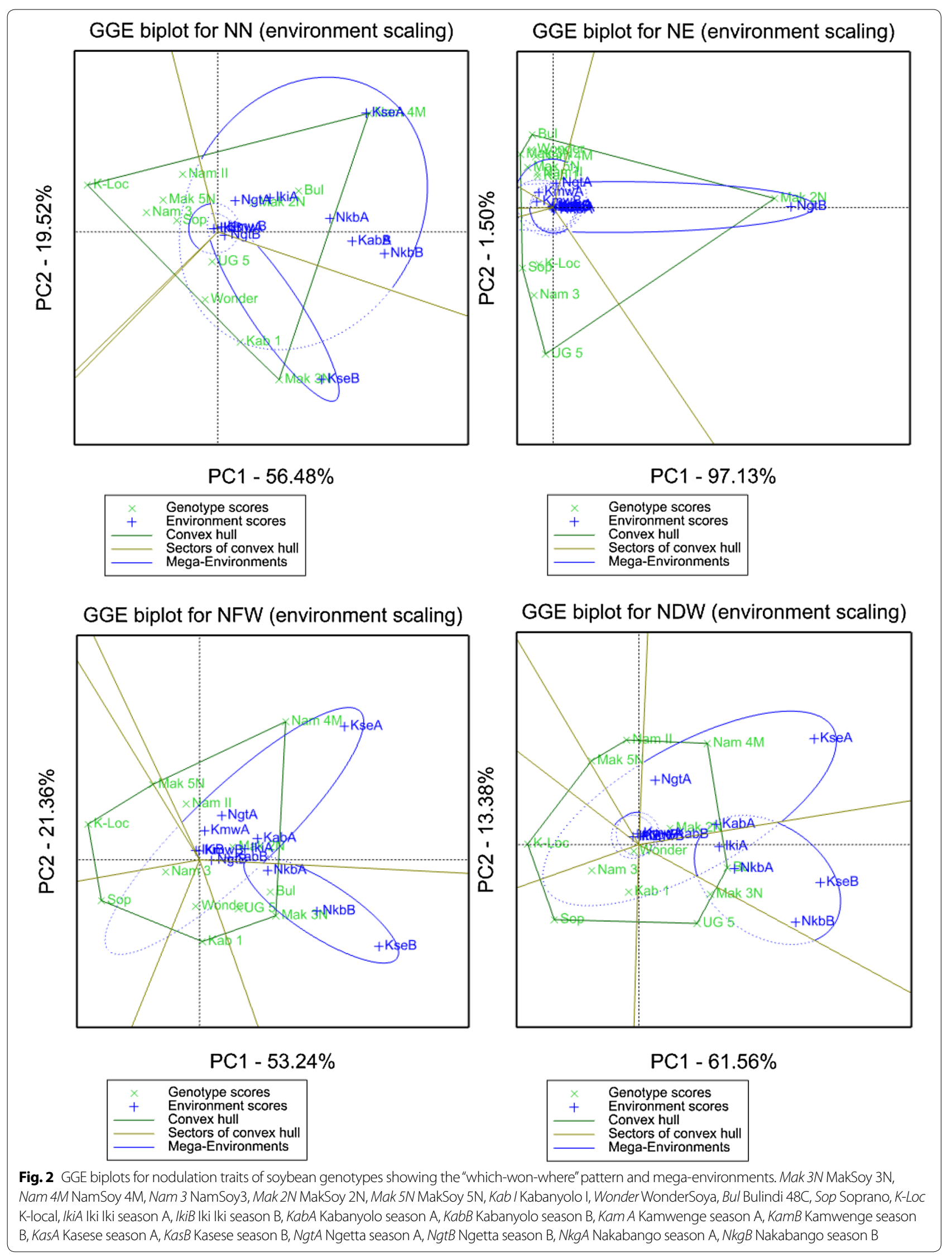


With respect to NFW, NamSoy 3 and WonderSoya proved the most stable (closest to the origin), the most unstable genotype was K-local, as it had the longest vector to the origin. The genotype NamSoy $4 \mathrm{M}$ had the best performance $(744 \mathrm{mg}$ ) and was relatively stable, while the genotype Soprano had the lowest performance (347 mg) and was unstable.

For NDW, the genotypes WonderSoya and Kabanyolo I were closest to the origin and thus were the most stable, while genotypes $\mathrm{K}$-local and Bulindi $48 \mathrm{C}$ had the longest vector to the origin and thus were the least stable. Genotype NamSoy $4 \mathrm{M}$ had the highest performance $(151 \mathrm{mg})$, while K-local had the lowest performance $(72 \mathrm{mg})$.

Focusing on the environments, Nakabango B was the environment with the highest nodule number, while Kamwenge A and B, as well as Ngetta B, had the lowest NN, followed by Ngetta A and Iki iki B, respectively. With respect to the NE, Kasese A had the greatest percentage of effective nodules, while Iki iki B had the lowest percentage. The highest fresh weight of nodules was found in Nakabango B and Kasese A, while Kamwenge $A$ and $B$ had the lowest performance. The highest fresh weight of nodules was observed in Kasese A and Nakabango B, while Kamwenge A and B had the lowest performance.

\section{Genotype and genotype by environment (GGE) biplot analysis}

The mean performance of genotypes for each nodulation trait across environments was subjected to the GGE analysis. The GGE biplots (Fig. 2) plotted the scores of genotypes and environments on the first (PC1) against the second (PC2).

The first axis (PC1) explained 56\% of the variation in $\mathrm{NN}$, while the second axis (PC2) explained 20\%. In total, the first two axes explained $76 \%$ of the total variation. The sector convex hull showed three sectors indicating three mega-environments: Kasese A, Nakabango A and B, Kabanyolo A and B, Iki Iki A, and Ngetta A made one mega-environment with NamSoy $4 \mathrm{M}$ the winning genotype. Kasese B represents the second mega-environment with MakSoy $3 \mathrm{~N}$ the highest performing genotype. The third mega-environment included Ngetta B, Iki Iki B, and Kamwenge A and B with K-local the best genotype in that mega-environment.
With respect to the percentage of effective nodules, the first two PCs explained $98.5 \%$ of the total variation of which PC1 had 97\% and the PC2 1.5\%. Three megaenvironments were demarcated: Ngetta B represented one mega-environment with MakSoy $2 \mathrm{~N}$ as winning genotype. Ngetta A and Kamwenge A and B formed the second mega-environment with Bulindi $48 \mathrm{C}$ and MakSoy $3 \mathrm{~N}$ as winning genotypes. The rest of the environments formed the third mega-environment with Soprano, NamSoy3 and UG5 as best genotypes.

For NFW, the first two PCs explained $75 \%$ of the total variation of which the $\mathrm{PC} 1$ carried $53 \%$. Two mega-environments were demarcated with Nakabango A and B, and Kasese B forming the first mega-environment with MakSoy $3 \mathrm{~N}$ as best genotype, and the rest of the environments constitute the second mega-environment in which NamSoy $4 \mathrm{M}$ was the best genotype.

The two first PCs explained $75 \%$ of the total variation in NDW. Four mega-environments were demarcated with interference between them. The largest mega-environment included Kasese A, Kabanyolo A and B, Ngetta A and B, Kamwenge A and B, and Iki Iki A and B. NamSoy $4 \mathrm{M}$ was the winning genotype in that mega-environment. However, Iki Iki A and Kabanyolo A also belong to the second mega-environment which they formed together with Kasese B and Nakabango A and B; Bulindi 48C and MakSoy $3 \mathrm{~N}$ were the winning genotype in this megaenvironment. The last two mega-environments were contiguous. They were formed with Kamwenge A and Iki Iki $B$ for one and Ngetta B and Kamwenge B for the other.

Overall Nakabango B proved the ideal environment for NN (Fig. 3a), Ngetta B for NE (Fig. 3b), while Kasese A proved the ideal environment for NFW (Fig. 3c) and Kasese B for NDW (Fig. 3d). These environments had the longest vector, so were the most discriminating; besides, they were the closest to the horizontal axis, so were representative of the other environments.

\section{Discussion}

The study showed highly significant interactions between genotypes and environments for all the nodulation traits measured. This is an indication that the response of promiscuous soybean genotypes to Bradyrhizobium sp. USDA 3456 is highly dependent on the site where the genotypes are grown and seasonal variation of temperature

(See figure on next page.)

Fig. 3 Discriminating biplots for nodulation traits of soybean genotypes showing the "ideal" environments. a Nodules number (NN), b nodules' effectiveness (NE), c nodules fresh weight (NFW), d nodules fresh weight (NDW). Mak 3N MakSoy 3N, Nam 4M NamSoy 4M, Nam 3 NamSoy 3, Mak 2N MakSoy 2N, Mak 5N MakSoy 5N, Kab I Kabanyolo I, Wonder WonderSoya, Bul Bulindi 48C, Sop Soprano, K-Loc K-local, IkiA Iki Iki season A, IkiB Iki Iki season B, KabA Kabanyolo season A, KabB Kabanyolo season B, Kam A Kamwenge season A, KamB Kamwenge season B, Kas A Kasese season A, KasB Kasese season B, NgtA Ngetta season A, NgtB Ngetta season B, NkgA Nakabango season A, NkgB Nakabango season B 


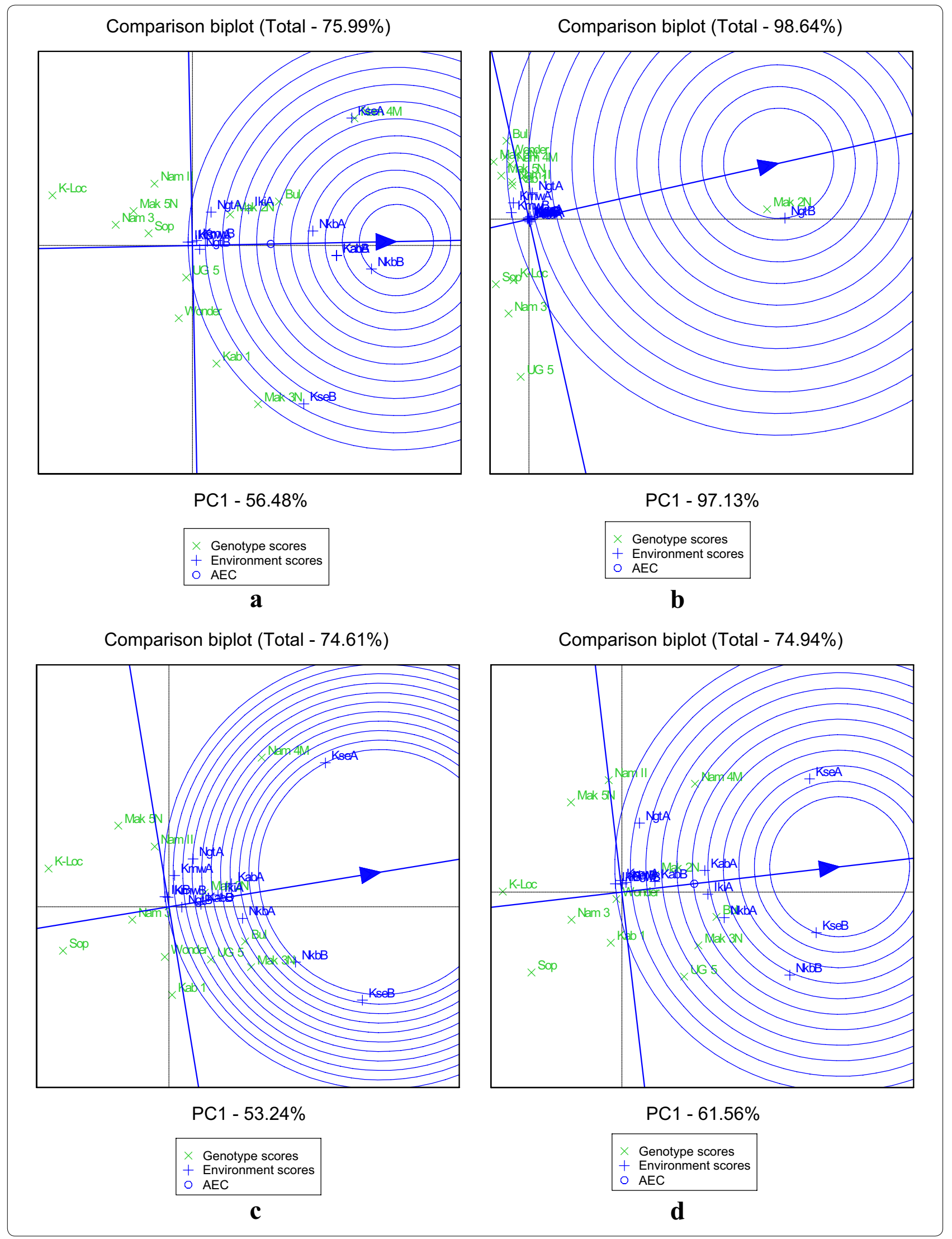


and rainfall. For most of the measured nodulation traits, the contribution of the environment to the total variation was higher than the effect of the genotypes and genotype by environment $(G \times E)$ interaction, except for percent of effective nodules where the $G \times E$ interaction effects contributed more to the total variation than the genotypes and environments effects. A similar trend was reported earlier on 31 Argentinean soybean genotypes by Salvucci et al. [9], who observed $41.9 \%$ contribution from environments against $28 \%$ from genotypes and $10.7 \%$ from interactions to the total variations on NN. However, the same authors reported more contribution from genotypes (30.5\%) than environments and $\mathrm{G} \times \mathrm{E}$ interaction, 14.6 and $13.5 \%$, respectively, in the total variation on NDW. The low contribution of the genotypes to the total variation observed in this study suggests that selection in a single environment may fail to achieve sufficient gain. Multi-environment selection is the best strategy suggested by quantitative geneticists to achieve selection gain with traits that exhibit low genetic effect $[7,8]$. One possible reason for genotypes accounting for relatively lower percentage of variability is the few genotypes (12) tested in this study; low genotype number leading to underestimation of genetic contribution has been pointed out by quantitative geneticists such as $[7,8]$. Increasing the number of genotypes might result in a higher genetic contribution to the total observed variability.

Several authors have reported the importance of the environmental effect on nodulation in diverse legume plants [29-31]. Van et al. [32] advocate that the interaction between soybean and Bradyrhizobia can be represented by the disease triangle, whereby a functioning equilibrium between the host plant, microorganism and the environment is important to achieve effective nodulation. Yusuf et al. [33] emphasized that nodulation in soybean is a result of the effect of these three components (genotypes, environment, and Bradyrhizobia) plus their interaction.

The GGE analysis showed that different seasons at the same site differ such that a site may belong to different mega-environments, depending on the season. This emphasizes the extent to which the environmental influences are important in the expression of these nodulation traits. Yan and Rajcan [34] defined an ideal environment as having high discriminating power (large PC1 scores) and being most representative of other environments (small PC2 scores). For the NN, Nakabango B was the most discriminating and representative environment, while Kasese B was ideal for NDW. A similar result was earlier reported on soybean yield in Uganda by Tukamuhabwa et al. [35]. These ideal environments are known to resolve accurate genotypic differences, thereby providing breeders with necessary information for selection [35].
The average performances of environments showed Kamwenge A, B, Ngetta A, B and Iki Iki B as the poorest performing. The consistently poor performance at Kamwenge and Ngetta needs further investigations. We speculated that the poor performance of these two sites (Kamwenge and Ngetta) could be attributed to soil characteristics and environmental factors. Factors such as soil acidity ( $\mathrm{pH}$ lower than 5.6), waterlogging, high temperatures, soil salinity, low available phosphorus and calcium, too much nitrogen, anoxia, etc. have been reported to affect nodulation in soybean $[36,37]$. However, no obvious differences in nutrient content and average rainfall between these two (Kamwenge and Ngetta) and other sites were observed. There is therefore no evidence linking weather or soil conditions to the poor performance of Kamwenge and Ngetta. Besides, authors reported that competition between indigenous and introduced strains can lead to failure in maximizing nodulation potential of soybeans [38]. Hence, we recommend that further research consider the characterization of soil Bradyrhizobia, especially at these two sites to explain the low performance of all the genotypes and suggest solutions to solve that. In Ngetta, galls due to infection by root knot nematodes (Meloidogyne incognita) were frequently observed on plants' root system. This could explain the relatively low nodulation recorded in that site, as competition for space and nutrients might have occurred. We also recommend that investigations be made on the interaction between Bradyrhizobia and root knot nematode.

\section{Conclusion}

This study revealed information that can guide breeding strategies. The nodulation scores measured were number of nodules (NN), percent of effective nodules (NE), fresh weight of nodules (NFW), and dry weight of nodules (NDW). The effect of the environment was high on nodulation traits measured, and the same applies to the $\mathrm{G} \times \mathrm{E}$ interaction. The genetic effect tends to be low compared to the environment effect and the $\mathrm{G} \times \mathrm{E}$ interaction. The genotypes UG5, Kabanyolo I, and WonderSoya, which each showed stability for some of the nodulation traits measured, can be recommended as parental lines to initiate a breeding program focusing on promiscuous nodulation in soybean. The low genetic contribution, high environmental effect, and $\mathrm{G} \times \mathrm{E}$ interaction observed in this study provide very important knowledge that will be insightful for further soybean breeding programs, as multi-environment testing of the genotypes for both cultivar selection and cultivar recommendation is necessary in such situations. In other hand, the study revealed that as far as promiscuous nodulation in soybean is concerned, the sites where this study was conducted should not stand alone as testing environments as it was shown 


\section{that the same site can behave as different environments depending on the season.}

\begin{abstract}
Abbreviations
AMMI: additive main multiplicative interaction; GGE: genotype and genotype by environment; ME: mega-environment; NN: nodules' number; NE: nodules' effectiveness; NFW: nodules' fresh weight; NDW: nodules' dry weight; G $\times E$ : genotypes by environment; USDA: United States Department of Agriculture; IPCA: interaction principal component axes; PC: principal component; BMS: Breeding Management System; RCBD: randomized complete block design; BNF: biological nitrogen fixation; MPN: most probable number (MPN); MUARIK: Makerere University Agricultural Research Institute of Kabanyolo; NZARDI: Ngetta Zonal Agricultural Research and Development Institute; NARO: National Agricultural Research Organization; MAK: Makerere University; ITA: International Institute for Tropical Agriculture; SHMM: shifted multiplicative model; JREG: joint regression; FREG: factorial regression; SREG: site regression; RAPD: randomly amplified polymorphic DNA.
\end{abstract}

\section{Authors' contributions}

EEA, TLO, JBT, GC, BWD, and PT conceived the study. EEA, JBT, and PT collected data. EEA and TLO analyzed data. All authors read and approved the final manuscript.

\section{Author details}

'Department of Agricultural Production, Makerere University, P.O. Box 7062, Kampala, Uganda. ${ }^{2}$ Department of Crop Science, University of Illinois, 1101 W Peabody Drive, Urbana, IL 61801, USA. ${ }^{3}$ International Institute of Tropical Agriculture IITA-Zambia, Plot 32, Poplar Avenue, Avondale, Lusaka, Zambia.

\section{Acknowledgements}

Our acknowledgment goes to Intra-ACP SHARE for its supports, to the BNF laboratory at Makerere University for the technical assistance, to Boris Alladassi, Fréjus Sodedji, and Symphorien Agbahoungba for their proofreading and fruitful discussions.

The authors do hereby declare that with the exception of references to past and current studies consulted which have been duly acknowledged, the work presented was carried out from April 2015 to January 2016 in Uganda.

\section{Competing interests}

The authors declare that they have no competing interests.

\section{Availability of supporting data}

The data generated and analyzed in this study are available to readers as in the manuscript.

\section{Funding}

EEA is a fellow of the Norman E. Borlaug Leadership Enhancement in Agriculture Program funded by USAID. Support for this research was provided in part by the Borlaug Leadership Enhancement in Agriculture Program (Borlaug LEAP) through a grant to the University of California-Davis by the United States Agency for International Development. The opinions expressed herein are those of the authors and do not necessarily reflect the views of USAID. Support for this research was made possible through a capacity building competitive grant Training the next generation of scientists provided by Carnegie Cooperation of New York through the Regional Universities Forum for Capacity Building in Agriculture (RUFORUM).

Received: 13 January 2017 Accepted: 10 March 2017 Published online: 17 March 2017

\section{References}

1. Bernardo R. Breeding for quantitative traits in plants. Woodbury: Stemma Press; 2002. ISBN: 10-0972072403.

2. Chandler K, Lipka AE, Owens BF, Li H, Buckler ES, Rocheford T, Gore MA. Genetic analysis of visually scored orange kernel color in maize. Crop Sci. 2013;53:189-200.
3. Gauch HG, Zobel RW. Identifying mega-environments and targeting genotypes. Crop Sci. 1997;37:311-26.

4. Yan W, Hunt LA. Genotype by environment interaction and crop yield. Plant Breed Rev. 1998;16:135-78.

5. Balzarini M, Bruno C, Arroyo A. Análisis de ensayos agrícolas multi-ambientales: Ejemplos con Info-Gen. Córdoba: Fac. de Cs. Agropec. U.N.C; 2005.

6. Ramalho MAP, Santos JB, Zimmermann MJO. Genética quantitativa em plantas autógamas: aplicações ao melhoramento do feijoeiro. Goiânia: UFG; 1993.

7. Bernardo, R. Essentials of plant breeding. Woodbury: Stemma Press; 2014. ISBN: 978-0-9720724-2-7.

8. Acquaah G. Principles of plant genetics and breeding. 2nd ed. New York: Wiley; 2012.

9. Salvucci RD, Aulicino M, Hungria M, Balatti PA. Nodulation capacity of Argentinean soybean (Glycine max L. Merr) cultivars inoculated with commercial strains of Bradyrhizobium japonicum. Am J Plant Sci. 2012;3:130-40.

10. Salvagiotti F, Cassman KG, Specht JE, Walters DT, Weiss A, Doberman A. Nitrogen uptake, fixation and response to fertilizer $\mathrm{N}$ in soybean: a review. Field Crops Res. 2008;108:1-13. http://tiny.cc/soybeanNreview.

11. Sanginga N, Dashiell K, Okogun JA, Thottappilly G. Nitrogen fixation and $\mathrm{N}$ contribution by promiscuous nodulating soybeans in the southern Guinea savanna of Nigeria. Plant Soil. 1997:195:257-66.

12. Hailu T. Breeding for promiscuous soybeans at ITA, soybean. In: Alexander S, editor. Molecular aspects of breeding. In Tech; 2011. http:// www.intechopen.com/books/soybean-molecular-aspects-of-breeding/ breeding-for-promiscuoussoybeans-at-IITA. Accessed 14 Apr 2014.

13. Pulver EL, Kueneman EA, Ranga-Rao V. Identification of promiscuous nodulating soybean efficient in $\mathrm{N}_{2}$ fixation. Crop Sci. 1985;25:660-3.

14. International Institute of Tropical Agriculture (IITA). Understanding nitrogen fixation in promiscuous soybean. In: Microbiology in the service of crops and soils. Annual report, IITA, Ibadan, Nigeria. 1996.

15. Gwata ET, Wofford DS, Pfahler PL, Boote KJ. Genetics of promiscuous nodulation in soybean: nodule dry weight and leaf color score. J Hered. 2004;95:154-7.

16. Abaidoo CR, Keyser HH, Singleton PW, Dulal BD. Bradyrhizobium spp. (TGX) isolates nodulating the new soybean cultivars in Africa are diverse and distinct from Bradyrhizobia that nodulate North American soybeans. Int J Syst Evol Microbiol. 2000;50:225-34.

17. Gwata ET, Wofford DS. Potential of RAPD analysis of the promiscuous nodulation trait in soybean (Glycine max L). Biol Fertil Soils. 2013;49:241-4.

18. Kandus M, Almorza D, Boggio RR, Salern JC. Statistical models for evaluating the genotype-environment interaction in maize (Zea mays L.). Phyton. 2010;79:39-46.

19. Gauch HG. Statistical analysis of yield trials by AMMI and GGE. Crop Sci. 2006;46:1488-500.

20. Gauch HG, Zobel RW. Predictive and postdictive success of statistical analyses of yield trials. Theor Appl Genet. 1988;76:1-10.

21. Shrestha J. Genotype by environment interaction and yield stability analysis of quality protein maize genotypes in Terai Region of Nepal. Int J Appl Sci Biotechnol. 2013;1:74-8.

22. Naroui Rad MR, Abdul Kadir M, Rafii MYH, Jaafar ZE, Naghavi MR, Farzaneh A. Genotype $x$ environment interaction by AMMI and GGE biplot analysis in three consecutive generations of wheat (Triticum aestivum) under normal and drought stress conditions. Aust J Crop Sci. 2013;7:956-61.

23. Gauch HG, Piepho HP, Annicchiarico P. Statistical analysis of yield trials by AMMI and GGE: further considerations. Crop Sci. 2008;48:866-89.

24. Agoyi EE, Afutu E, Tumuhairwe JB, Odong TL, Tukamuhabwa P. Screening soybean genotypes for promiscuous symbiotic association with Bradyrhizobium strains. Afr Crop Sci J. 2016;24:49-59. doi:10.4314/acsj.v23i4.1.

25. Tukamuhabwa P, Obua T. Soybean: production guide in Uganda. Uganda: Makerere University; 2015.

26. Somasegaran P, Hoben HJ. Handbook for rhizobia: methods in legumerhizobium technology. New York: Springer; 1994.

27. Payne RW, Harding SA, Murray DA, Soutar DM, Baird DB, Glaser Al. The guide to Genstat release 14, part 2: statistics. Hemel Hempstead: VSN International; 2011.

28. Breeding View by VSN International Ltd. Versions: 1.9. 2015. https://www. integratedbreeding.net/.

29. Lie TA. Environmental effects on nodulation and symbiotic nitrogen fixation. In: Quispel A, editor. The biology of nitrogen fixation. Amsterdam: North Holland; 1974. p. 555-82. 
30. Silvester WB. Analysis of nitrogen fixation. In: Gordon JC, Wheeler CT, editors. Biological nitrogen fixation in forest ecosystems: foundations and applications. Dordrecht: Nijhoff/Junk; 1983. p. 173-212.

31. Nicolás MF, Carlos A, Arrabal A, Hungria M. Genetics of nodulation and nitrogen fixation in Brazilian soybean cultivars. Biol Fertil Soils. 2002;36:109-17. doi:10.1007/s00374-002-0511-3.

32. Van K, Kim MY, Lee SH. Genomic of root nodulation. Genomics Assist Crop Improv. 2007;2:435-52.

33. Yusuf AA, Abaidoo RC, Iwafor ENO, Olufajo OO. Genotype effects of cowpea and soybean on nodulation, $\mathrm{N}_{2}$-fixation and $\mathrm{N}$ balance in the Northern Guinea Savanna of Nigeria. J Agron. 2008;7:258-64. doi:10.3923/ ja.2008.258.264.

34. Yan WK, Rajcan I. Biplot analysis of test sites and trait relations of soybean in Ontario. Crop Sci. 2002;42:11-20.
35. Tukamuhabwa P, Assiimwe M, Nabasirye M, Kabayi P, Maphosa M. Genotype by environment interaction of advanced generation soybean lines for grain yield in Uganda. Afr Crop Sci J. 2012;20:107-15.

36. Graham PH. Plant factors affecting nodulation and symbiotic nitrogen fixation in legumes. In: Alexander M, editor. Biological nitrogen fixation. New York: Plenum Press; 1984.

37. Eaglesham ARJ, La Favre AK. Aspects of the physiology of combined-N inhibition of soybean nodulation. In: Evans HJ, Bottomley PJ, Newton WE, editors. Nitrogen fixation research progress. Dordrecht: Springer; 1985. p. 315-21. doi:10.1007/978-94-009-5175-4_44.

38. Ge C, Xu L. Observation of the infection behavior of indigenous Rhizobium japonicum and its distribution in different varieties of soybean in the fields. Chin Oil Crops. 1982;3:56-8.

\section{Submit your next manuscript to BioMed Central and we will help you at every step:}

- We accept pre-submission inquiries

- Our selector tool helps you to find the most relevant journal

- We provide round the clock customer support

- Convenient online submission

- Thorough peer review

- Inclusion in PubMed and all major indexing services

- Maximum visibility for your research

Submit your manuscript at www.biomedcentral com/submit 